\title{
X-ray photoelectron spectroscopy study of irradiation-induced amorphizaton of $\mathrm{Gd}_{2} \mathrm{Ti}_{2} \mathrm{O}_{7}$
}

\author{
J. Chen, J. Lian, L. M. Wang, and R. C. Ewing ${ }^{\text {a) }}$ \\ Department of Nuclear Engineering and Radiological Sciences, University of Michigan, Ann Arbor, \\ Michigan 48109-2104
}

\section{A. Boatner}

Solid State Division, Oak Ridge National Laboratory, Oak Ridge, Tennessee 37831-6056

(Received 27 April 2001; accepted for publication 23 July 2001)

\begin{abstract}
The radiation-induced evolution of the microstructure of $\mathrm{Gd}_{2} \mathrm{Ti}_{2} \mathrm{O}_{7}$, an important pyrochlore phase in radioactive waste disposal ceramics and a potential solid electrolyte and oxygen gas sensor, has been characterized using transmission electron microscopy and x-ray photoelectron spectroscopy. Following the irradiation of a $\mathrm{Gd}_{2} \mathrm{Ti}_{2} \mathrm{O}_{7}$ single crystal with $1.5 \mathrm{MeV} \mathrm{Xe}{ }^{+}$ions at a fluence of 1.7 $\times 10^{14} \mathrm{Xe}^{+} / \mathrm{cm}^{2}$, cross-sectional transmission electron microscopy revealed a 300-nm-thick amorphous layer at the specimen surface. X-ray photoelectron spectroscopy analysis of the Ti $2 p$ and $\mathrm{O} 1 s$ electron binding energy shifts of $\mathrm{Gd}_{2} \mathrm{Ti}_{2} \mathrm{O}_{7}$ before and after amorphization showed that the main results of ion-irradiation-induced disorder are a decrease in the coordination number of titanium and a transformation of the $\mathrm{Gd}-\mathrm{O}$ bond. These features resemble those occurring in titanate glass formation, and they have implications for the chemical stability and electronic properties of pyrochlores subjected to displacive radiation damage. (C) 2001 American Institute of Physics.
\end{abstract} [DOI: $10.1063 / 1.1402647]$

Isometric pyrochlore $(F d 3 m)$, ideally $\mathrm{A}_{2} \mathrm{~B}_{2} \mathrm{O}_{7}$, is a derivative of the fluorite structure $\left(\mathrm{AX}_{2}\right)$, but with two cations and one eighth of the oxygen absent. The A- and B-site cations are at equivalent positions, but there are two different types of oxygen. The first type of oxygen ( $48 f$ ) has two A-cation neighbors and two B-cation neighbors. The second type $(8 b)$ is on a tetrahedral site that is surrounded entirely by A cations. ${ }^{1,2}$ Pyrochlore oxides have a remarkable range of physical, chemical, and electronic properties depending on their composition and the degree of disorder on the cation sites. Tuller and Moon ${ }^{3}$ have shown that the isovalent substitution of $\mathrm{Zr}$ for $\mathrm{Ti}$ in $\mathrm{Gd}_{2}\left(\mathrm{Ti}_{x} \mathrm{Zr}_{1-x}\right)_{2} \mathrm{O}_{7}$ results in a 4.5 orders-of-magnitude increase in the oxygen ion conductivity at $600{ }^{\circ} \mathrm{C}$, as compared to the intrinsically poor ion conductor, pure $\mathrm{Gd}_{2} \mathrm{Ti}_{2} \mathrm{O}_{7}$. Thus, the $\mathrm{Gd}_{2}\left(\mathrm{Ti}_{x} \mathrm{Zr}_{1-x}\right)_{2} \mathrm{O}_{7}$ binary system has received considerable attention as a solid electrolyte ${ }^{4}$ and as an oxygen gas sensor. ${ }^{5}$ Recently, Wang et al. ${ }^{6}$ have found that pyrochlores become increasingly irradiation resistant with increasing $\mathrm{Zr}$ content in the $\mathrm{Gd}_{2}\left(\mathrm{Ti}_{x} \mathrm{Zr}_{1-x}\right)_{2} \mathrm{O}_{7}$ system when subjected to $1 \mathrm{MeV} \mathrm{Kr}^{+}$irradiation. This suggests the potential use of $\mathrm{Gd}_{2}\left(\mathrm{Ti}_{x} \mathrm{Zr}_{1-x}\right)_{2} \mathrm{O}_{7}$ as an oxygen sensor for applications in high irradiation environments. Considering the excellent conductivity properties and displacive radiation resistance of $\mathrm{Gd}_{2}\left(\mathrm{Ti}_{x} \mathrm{Zr}_{1-x}\right)_{2} \mathrm{O}_{7}$, it is also a potential material for use in fuel cells in space. ${ }^{7}$ More recently, Wang et $a{ }^{8}{ }^{8}$ have shown that the defect fluorite-structure type $\left(\mathrm{A}_{4} \mathrm{X}_{7}\right)$ can be produced by disordering the cations in $\mathrm{Gd}_{2} \mathrm{Ti}_{2} \mathrm{O}_{7}$ by ion irradiation suggesting that ion-beam irradiation can be used to modify the electronic/ionic conduction properties of pyrochlores.

In the present work, we report the microstructural

a)Electronic mail: rodewing@umich.edu changes of the end member composition $\mathrm{Gd}_{2} \mathrm{Ti}_{2} \mathrm{O}_{7}$ before and after ion irradiation by using x-ray photoelectron spectroscopy (XPS) and cross-sectional transmission electron microscopy (TEM) to follow the evolution of the structural disorder as a functional of displacive radiation dose.

The ion irradiation of the bulk samples was carried out using the HVEM-Tandem Accelerator Facility ${ }^{9}$ at the Argonne National Laboratory. The samples $(\sim 2 \mathrm{~mm}$ in diameter) were irradiated by $1.5 \mathrm{MeV} \mathrm{Xe}^{+}$ions to an ion fluence of $1.7 \times 10^{14} \mathrm{Xe}^{+} / \mathrm{cm}^{2}$.

The ex situ cross-sectional TEM observation of the samples was conducted using a JEOL 4000 EX electron microscope operated at an accelerating voltage of $400 \mathrm{keV}$, and XPS investigations were performed using an ESCA LAB5 XPS spectrometer with a $\mathrm{Mg} K \alpha$ x-ray source ( $h v$ $=1253.6 \mathrm{eV}) . \mathrm{Ar}^{+}$sputtering was used to remove carbon and surface contamination. The sputtering time was $3 \mathrm{~min}$ in

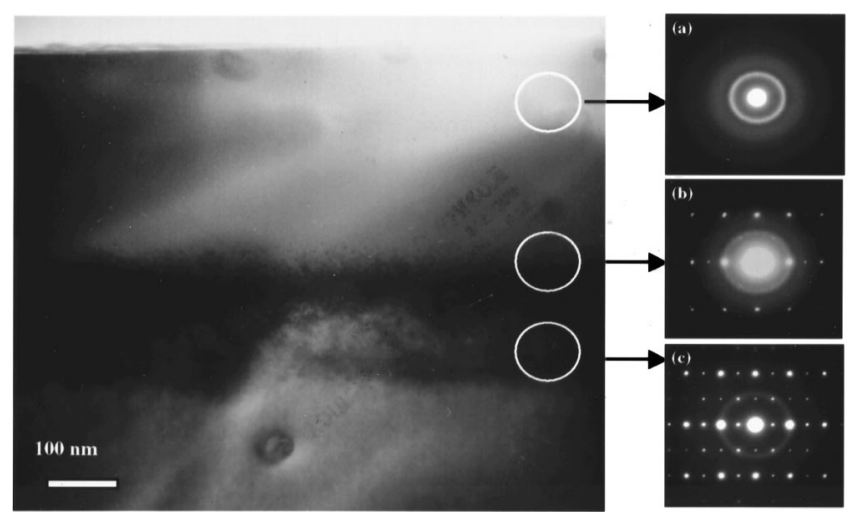

FIG. 1. Cross-sectional TEM image of irradiated $\mathrm{Gd}_{2} \mathrm{Ti}_{2} \mathrm{O}_{7}$ showing $\sim 300 \mathrm{~nm}$ amorphous surface layer. A highly damaged layer exists at the end of the range and consists of mixed pyrochlore/fluorite domains. 

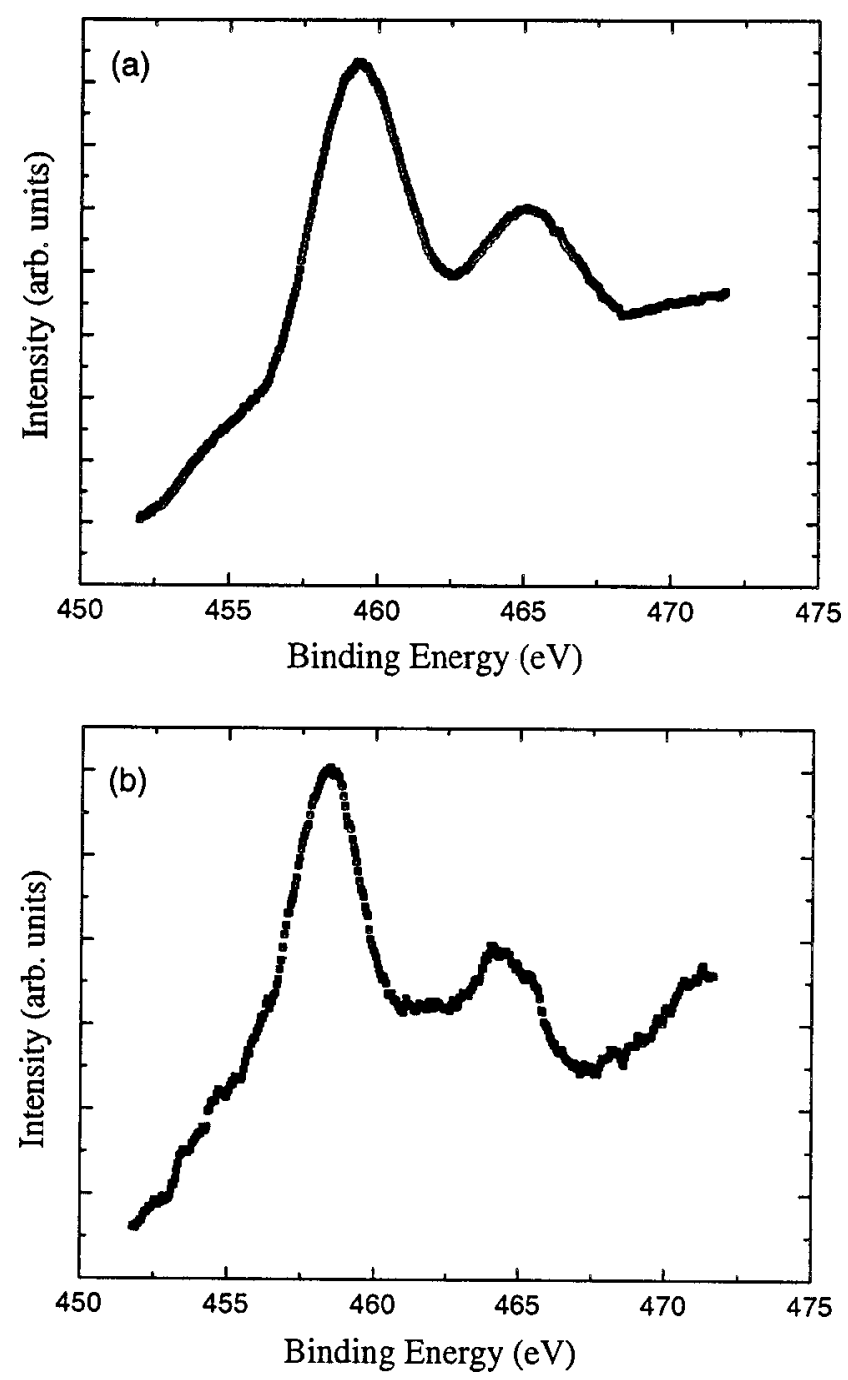

FIG. 2. Ti $2 p$ XPS spectra of $\mathrm{Gd}_{2} \mathrm{Ti}_{2} \mathrm{O}_{7}$ single crystal: (a) before ion irradiation, the binding energies of Ti $2 p_{3 / 2}$ and Ti $2 p_{1 / 2}$ are 459.4 and $465.2 \mathrm{eV}$, respectively; (b) After ion irradiation, the binding energies of Ti $2 p_{3 / 2}$ and $\mathrm{Ti}$ $2 p_{1 / 2}$ are 458.4 and $464.3 \mathrm{eV}$, respectively.

order to control the etching depth to less than $10 \mathrm{~nm}$. A carbon layer was deposited onto the surface of the sample holder in order to calibrate the binding energy shifts resulting from surface charging effects.

The cross-sectional TEM image and electron diffraction pattern of irradiated $\mathrm{Gd}_{2} \mathrm{Ti}_{2} \mathrm{O}_{7}$ after $1.5 \mathrm{MeV} \mathrm{Xe}^{+}$irradiation at $1.7 \times 10^{14}$ ions $/ \mathrm{cm}^{2}$ is shown in Fig. 1. A 300 -nm-thick amorphous layer was formed at the surface of the $\operatorname{Gd}_{2} \mathrm{Ti}_{2} \mathrm{O}_{7}$ crystal. Beneath the amorphous layer, there is a highly damaged layer showing dark contrast where the displacement damage level was lower than the critical amorphization dose (0.12 dpa). The selected-area-diffraction (SAD) pattern of this region [as illustrated in Fig. 1(b)] reveals mixed amorphous, fluorite- and pyrochlore-structure domains. The SAD pattern of the area located under this heavily damaged layer exhibits a mixed pyrochlore structure and partially amorphous material characteristics.

Due to the short inelastic mean free path (IMFP) and sensitivity to chemical surroundings of the photoelectrons, XPS is used for the characterization of changes in the chemical environment of an element in a structure, especially in the case of amorphous materials. The IMFP of a photoelec-
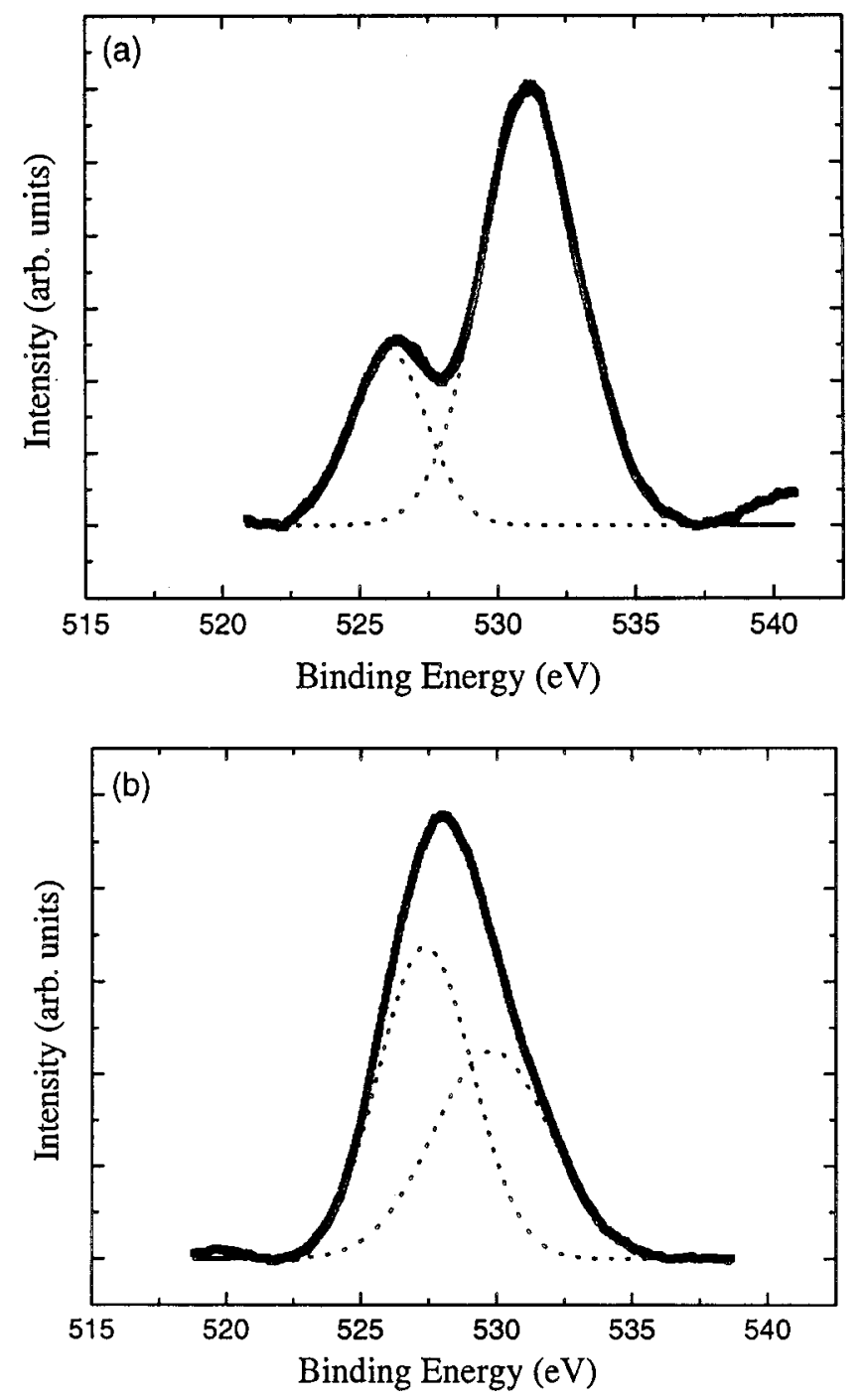

FIG. 3. O $1 s$ XPS spectra of $\mathrm{Gd}_{2} \mathrm{Ti}_{2} \mathrm{O}_{7}$ single crystal. The spectra can be fitted by two Gaussian functions: (a) prior to irradiation, the binding energies corresponding to the two Gaussian peaks are 526.1 and $531.2 \mathrm{eV}$, respectively; (b) after ion irradiation, the binding energies corresponding to the two Gaussian peaks are 527.3 and $529.9 \mathrm{eV}$, respectively. (- experimental data; $\cdots$ fitted curves)

trons is a function of its kinetic energy. The typical range of energies of the photoelectron is $100-1000 \mathrm{eV}$; the IMFP is on the order $0.5-5 \mathrm{~nm}$ in oxides. ${ }^{10}$ This ensures that the XPS signal comes only from the amorphous layer at the surface of the irradiated sample. Figure 2 shows the XPS spectra of the binding energy of Ti $2 p$ electrons vs the intensity before and after ion irradiation. The binding energy of $\mathrm{Ti} 2 p_{3 / 2}$ decreases from 459.4 to $458.4 \mathrm{eV}$ and that of Ti $2 p_{1 / 2}$ decreases from 465.2 to $464.3 \mathrm{eV}$ after ion irradiation. The decrease in binding energy of an element is the consequence of the increase in the effective negative charge on it. ${ }^{11}$ In the present case, the decrease in binding energy of Ti $2 p$ electrons indicates an increase in the average electron density on the titanium, which implies that the chemical characteristic of the $\mathrm{Ti}-\mathrm{O}$ bond has changed from that of ionic to more covalent after ion irradiation. This result is expected, because if $\mathrm{Ti}^{4+}$ plays the role of a glass former, it must decrease its coordination number and increase the degree of covalence of the $\mathrm{Ti}-\mathrm{O}$ bond in order to lead to glass formation. According to Zachariasen's model, ${ }^{12} \mathrm{TiO}_{2}$ cation is an intermediate oxide 
or network-modifying oxide because it does not form a glass by itself. However, it is known that many binary and ternary titanates consisting of $\mathrm{TiO}_{2}$ and network-modifying or intermediate oxides form a glass without the need for a networkforming oxide by quenching. ${ }^{13,14} \mathrm{X}$-ray radial distribution function analysis and Raman spectroscopic measurements in the system of $\mathrm{R}_{2} \mathrm{O}(\mathrm{RO})-\mathrm{TiO}_{2}$ indicated that $\left[\mathrm{TiO}_{4}\right]$, [ $\left.\mathrm{TiO}_{5}\right]$, or both were responsible for the formation of glass, and, especially, that $\left[\mathrm{TiO}_{4}\right]$ enhanced glass formation. ${ }^{15,16}$ This demonstrates that the conditions for the formation of these binary titanate glasses are, first, the possibility of a decrease in the coordination number of titanium from $\left[\mathrm{TiO}_{6}\right]$ to $\left[\mathrm{TiO}_{5}\right]$ or $\left[\mathrm{TiO}_{4}\right]$ and, second, a rapid cooling rate.

In recent years, molecular dynamics simulations of the heavy particle irradiation of solids have shown that, after the initial collisional process, a region of the atomic disorder in the collision cascade is created. ${ }^{17-19}$ The disordered region within the collision cascade is sometimes viewed as a hot, transient, almost "liquid-like zone." The energy within the cascade dissipates rapidly into the surrounding matrix in tens of pico-seconds. This quenching rate is much higher than that of the above-mentioned quenching methods. The structural changes before and after ion irradiation, indicated by the Ti $2 p$ XPS results, show similarities between the ionbeam-induced amorphization of $\mathrm{Gd}_{2} \mathrm{Ti}_{2} \mathrm{O}_{7}$ and the structural features produced by titanate glass formation. The changes in the binding energy $\mathrm{O} 1 s$ electrons show similar features. As shown in Fig. 3, the spectrum of binding energy vs the intensity of $\mathrm{O} 1 s$ spectrum has two obvious peaks prior to ion irradiation. This is consistent with the two types of $\mathrm{O}^{2-}$ coordination geometries in the $\mathrm{Gd}_{2} \mathrm{Ti}_{2} \mathrm{O}_{7}$ pyrochlore. According to the pyrochlore structure description outlined at the beginning of this letter, there are two types of cation-anion bonds, $\mathrm{Ti}-\mathrm{O}, \mathrm{Gd}-\mathrm{O}$. Considering the lower electronegativity of $\mathrm{Gd}^{3+}$ as compared with that of $\mathrm{Ti}^{4+}$, the ionic character of the $\mathrm{Gd}-\mathrm{O}$ bond is greater than that of the Ti-O bond. Thus, we assign the peak of $\mathrm{O} 1 s$ spectrum with low binding energy to oxygen anions bonded to gadolinium, while the peak of $\mathrm{O} 1 s$ spectrum with the higher binding energy is assigned to Ti-O. The corresponding $\mathrm{O} 1 s$ curves are shown as two fitted Gaussian functions in Fig. 3(a), respectively. After ion irradiation [Fig. 3(b)], the two peaks merge into a single peak. Although this $\mathrm{O} 1 s$ spectrum is not symmetric and can still be fitted with two Gaussian functions, the smaller difference in binding energies between the two Gaussian functions shows that, after ion irradiation, the chemical surroundings of the two types of oxygen sites become similar. When the pyrochlore oxides are subjected to ion irradiation, the cation disordering between the $\mathrm{A}$ and $\mathrm{B}$ sites occurs, thus the chemical environment of all of the oxygen anions becomes more similar. XPS results support the link between cation and anion disordering. After ion irradiation, the $\mathrm{O} 1 \mathrm{~s}$ electron binding energy assigned to the $\mathrm{Ti}-\mathrm{O}$ unit decreased from 531.2 to $529.9 \mathrm{eV}$. This decrease in binding energy indicates an increase of the effective negative charge on the oxygen anion. Thus, shortening of the Ti-O bond length is suggested. This means that the coordination number of the titanium polyhedron should decrease to match the changes in the $\mathrm{Ti}-\mathrm{O}$ bond length. The increase in the $\mathrm{O} 1 s$ electron binding energy assigned to $\mathrm{Gd}-\mathrm{O}$ (Fig. 3, from 526.1 to $527.3 \mathrm{eV}$ ) suggests that the $\mathrm{Gd}-\mathrm{O}$ bond becomes more covalent after irradiation.

In a study of a closely related material, monoclinic zirconolite $\left(\mathrm{CaZrTi}_{2} \mathrm{O}_{7}\right)$, Lumpkin et al. ${ }^{20}$ have found a $25 \%$ $40 \%$ reduction in coordination number at the $\mathrm{Ca} \mathrm{A}$ site with a corresponding $2 \%$ reduction in average bond length, as compared with an approximately $25 \%$ reduction in coordination number and a $7 \%$ bond length shortening at the Ti $\mathrm{B}$ site using the results of an extended $\mathrm{x}$-ray absorption fine structure spectroscopy study. Recently, Farges ${ }^{21}$ has reported that fivefold coordinated Ti was the dominant titanium species in metamict zirconolite using x-ray absorption near edge structure analysis. The results of the above studies of bulk amorphous material are consistent with our results for ionirradiation-amorphized titanate pyrochlore.

In summary, the binding energy changes of Ti $2 p$ and $\mathrm{O}$ $1 s$ electrons of $\mathrm{Gd}_{2} \mathrm{Ti}_{2} \mathrm{O}_{7}$ before and after $1.5 \mathrm{MeV} \mathrm{Xe}^{+}$irradiation show that the amorphization of $\mathrm{Gd}_{2} \mathrm{Ti}_{2} \mathrm{O}_{7}$ results in a decrease in the coordination number of titanium and an increase in the covalent character of the $\mathrm{Gd}-\mathrm{O}$ bond. That is, titanium polyhedra with a smaller coordination number will replace $\left[\mathrm{TiO}_{6}\right]$ in the amorphous structure of $\mathrm{Gd}_{2} \mathrm{Ti}_{2} \mathrm{O}_{7}$ under ion irradiation. These structural properties found for ionbeam-amorphized $\mathrm{Gd}_{2} \mathrm{Ti}_{2} \mathrm{O}_{7}$ are similar to those characteristics of titanate glasses.

This work was supported by the Office of Basic Energy Sciences, USDOE under DOE Grant No. DE-FG0297ER45656. Oak Ridge National Laboratory is managed by UT-Battelle, LLC, for the USDOE under Contract No. DEAC05-00OR22725. One of the authors (J.C.) thanks R. G. Wang for his assistance in XPS analysis at Peking University in China.

${ }^{1}$ L. Minervini and R. W. Grimes, J. Am. Ceram. Soc. 83, 1873 (2000).

${ }^{2}$ B. J. Wuensch and K. W. Eberman, JOM52, 19 (2000).

${ }^{3}$ H. L. Tuller and P. K. Moon, Mater. Sci. Eng., B 1, 171 (1988).

${ }^{4}$ H. L. Tuller, J. Electroceram. 1, 211 (1997).

${ }^{5}$ P. K. Moon and H. L. Tuller, Sens. Actuators B 1, 199 (1990).

${ }^{6}$ S. X. Wang, B. D. Begg, L. M. Wang, R. C. Ewing, W. J. Weber, and K. V. G. Kutty, J. Mater. Res. 14, 4470 (1999).

${ }^{7}$ M. Ishimar, I. V. Afanasyev-Charki, and K. E. Sickafus, Appl. Phys. Lett. 76, 2556 (2000).

${ }^{8}$ S. X. Wang, L. M. Wang, R. C. Ewing, and K. V. G. Kutty, Nucl. Instrum. Methods Phys. Res. B 169, 135 (2000).

${ }^{9}$ A. Taylor, C. W. Allen, and E. A. Kyan, Nucl. Instrum. Methods Phys. Res. B 24/25, 598 (1987).

${ }^{10}$ Experimental Techniques of Glass Science, edited by C. J. Simmons and O. H. EI-Bayoumi (The American Ceramic Society, Westerville, OH, 1993).

${ }^{11}$ P. W. Wang and L. Zhang, J. Non-Cryst. Solids 194, 129 (1996).

${ }^{12}$ W. H. Zachariasen, J. Am. Chem. Soc. 54, 3841 (1932).

${ }^{13}$ Bh. V. J. Rao, J. Am. Ceram. Soc. 47, 455 (1976).

${ }^{14}$ P. T. Sarjeant and R. Roy, J. Am. Ceram. Soc. 52, 57 (1969).

${ }^{15}$ S. Saka, F. Miyaji, and K. Fukumi, J. Non-Cryst. Solids 107, 171 (1989).

${ }^{16}$ F. Miyaji, T. Yoko, H. Kozuka, and S. Saka, J. Mater. Sci. 26, 248 (1991).

${ }^{17}$ F. Desauer, Z. Phys. 38, 12 (1923).

${ }^{18}$ T. Diaz de la Rubia and G. H. Gilmer, Phys. Rev. Lett. 74, 2507 (1995).

${ }^{19}$ R. S. Averback and M. Ghaly, J. Appl. Phys. 76, 3908 (1994).

${ }^{20}$ G. R. Lumpkin, R. C. Ewing, B. C. Chakoumakos, R. B. Greegor, F. W. Lytle, E. M. Foltyn, F. W. Clinard, Jr, L. A. Boatner, and M. M. Abraham, J. Mater. Res. 1, 564 (1986).

${ }^{21}$ F. Farges, Am. Mineral. 82, 44 (1997). 